\title{
Construction of Real-time Interactive Mode-based Online Course Live Broadcast Teaching Platform for Physical Training
}

\author{
https://doi.org/10.3991/ijet.v13i06.8583 \\ Jianqiu Liu \\ Bengbu Medical College, Bengbu, Anhui, China \\ 815568519 @qq.com
}

\begin{abstract}
As a new teaching mode, online courses have become one of the most important teaching methods in higher education. At present, there are still some shortcomings in online course live broadcast teaching platform including insufficient hardware support, low flexibility and weak interactivity. Meanwhile, during the entire online course teaching process, teachers do not know the overall learning effect of students in real time to determine the next teaching plan. This study presented a real-time interactive technology to enhance the interactive of the entire online course broadcast teaching platform. At the same time, it combined a monitoring method for online course terminals, servers and learning process to demonstrate students' learning effect in the whole online course learning process, and finally built the online course broadcast teaching platform. The practice test in teaching shows that the online course broadcast teaching platform can improve the teaching effect among students, which is of great significance for the improvement of teaching quality.
\end{abstract}

Keywords-Real-time interaction mode; Physical Training teaching; Network course

\section{$1 \quad$ Introduction}

The emergency of internet at the end of the 20th century has brought the development of information technology. With the development of information technology, the functions provided by internet become more and more. Online multimedia technology, also called network course technology, can effectively serve for coursed teaching [1]. Its difference with multimedia technology in routine teaching work is that, offline multimedia technology conducts corresponding teaching presentation through multimedia system in teaching work, and corresponding teaching tasks can be completed through real-time display on the computer. Carrying out corresponding teaching task through multimedia technology is called single offline teaching. With the development of information technology, more and more teaching functions can be achieved through internet. So, network course live broadcast teaching platform as a new online course teaching platform suitable for internet development requirements was born. 
In the whole network course operation, the interaction between teachers and students is the most important factor. Network course live broadcast teaching platform proposed in this paper takes Physical Training network course as the main object of study. This course aims to serve as the training foundation of different physical training, enhance basic skills of physical trainers and correct students' postures in physical training. Based on the teaching objective of Physical Training, real-time information exchange between teachers and students is required, which is also the basis of interaction mode of this network course live broadcast teaching platform. Only with such interaction mode, the whole network teaching platform can improve students' learning efficiency and effect. Meanwhile, the users of network course platform can really learn corresponding course knowledge, and the talents with professional knowledge can be provided for the society.

\section{State of the art}

From 1980s (before the birth of internet), some large IT companies in science and technology powers such as US, Japan and Europe started to conduct online multimedia teaching. The final idea of these internet companies was to form an online multimedia platform with rich information resources by which users could communicate with each other [2]. Based on the researches of these companies, they first invested and established LAN-based multimedia communication systems which could implement speech communication within certain network scope. The most mature system was Etherphone communication system of American Xerox Company [3]. With the research on online multimedia teaching, small-scale LAN gradually developed into internet in 1990s. World Wide Web greatly promoted the research on network multimedia platform. American VocalTec Company first launched IP phone software called Internet Phone. Such IP phone software as the earliest online multimedia communication platform has become the earliest exploration of these internet companies [4].

Except the demand for online multimedia voice communication, people are not satisfied with pure online voice communication, with the gradual development of internet and continuous improvement of internet functions. People further need face-toface video communication. The software which can online transmit audio/video information such as videophone and video conference gradually emerged. With the emergency of such software, hardware industry of network multimedia technology has gained corresponding development: Toshiba Corporation took the lead to develop MPEG-4 coding and decoding chips, which laid a foundation for the development of light and mobile multimedia equipment [5]. Motorola also applied the chip in mobile phone. Corresponding film resources could be watched in real time on the phone launched by Motorola. This is also the prototype of network broadcast. The network course live broadcast also referred to it.

In foreign countries, live broadcast teaching system becomes the research emphasis of distance classroom education institutions, because of the development of distance education technology. As continuous researches, the researches on network course 
live broadcast teaching gradually developed to intelligence, modularization, automation and virtualization. Network course live broadcast teaching system gained great development in US. At present, all states in US have established corresponding live broadcast teaching system. Western Virginia real-time teaching application platform (WVVS) has been established to make education free from the restriction of school scale, time and space and offer rich and complete course education for students anytime and anywhere [6]. Colombi [7] applied network live broadcast course in dance teaching, and constructed a virtual discussion zone for students on the basis of Blackboard online course. The result shows that the network course could enhance students' learning effect. Freguia [7] applied network live broadcast course in engineering course and environmental protection teaching and found that students held positive attitude to webcasts: the proportion of students viewing the webcast in advance was $80 \%-92 \%$ over the five weeks of the intervention. Enhanced engagement brought increasing attendance $(85-92 \%)$, and prominent active participation in class (half of observed teams $(\sim 80 \%)$ were active). Sato [9] surveyed the experiences of PE teachers in online adapted physical education (APE) postgraduate courses and the final theme assessment experiences, and depicted the process in which the participants learned knowledge and skills through online courses about assessment and evaluation. The result indicates that the course contributes to teaching and can be further promoted and applied.

Numerous internet companies developed network education products, and online education products synthesizing real-time teaching and online interaction functions sprang up, such as MPEG2 network teaching live broadcast and VOD scheme [10]. The network teaching live broadcast and VOD scheme aims to meet teaching demand of platform users. MPEG-2 video technology is used to transmit corresponding courses in real time. Students can view course live broadcast and rebroadcast through campus LAN. However, due to the insufficient amount of video compression, the data size is too large in each course, and the course could not transmitted on internet in real time. Streaming media technology has become the mainstream of network video live broadcast technology. The technology can effectively save storage space and reach corresponding continuous transmission. At present, streaming media technology has been fully utilized on network live broadcast platform. Chinese educational institutions such as New Oriental and Sailing have applied streaming media technology to establish network course live broadcast teaching platform with thorough functions [11].

With the development of information technology, network course live broadcast teaching platform still has the defect of insufficient interactivity. In the whole teaching process, there are only a few teachers. However, since the scope of audiences is very large, teachers cannot exchange with every student in real time. Real-time interaction must be supported by corresponding software. It lacks flexibility on the whole, so it is not suitable for large-scale promotion [12]. Moreover, the teacher cannot know students' learning effect in real time so as to confirm the next teaching plan in the operation process of network live broadcast platform, for the teacher and students are in the one-to-more relationship. For the above two problems, this paper, on the one hand, proposes a real-time interaction technique to improve interactivity of network 
course live broadcast teaching platform. On the other hand, this paper combine a monitoring method used for network course terminal, server and learning process to feedback students' learning effect so as to improve the learning method and enhance learning efficiency. Through network course live broadcast platform, students can learn more knowledge and more network education talents can be provided for the society.

\section{Theoretical construction}

\subsection{Real-time interaction technology}

Real-time interaction technology owns multiple interaction modes. The interaction mode used by video capture interaction module is H.263 coding and decoding technology. Audio acquisition and playing adopt G.729 coding and decoding technology. The feature of H.263 coding and decoding technology is that information compression ratio and image quality can improve greatly, and compression efficiency in information transfer process can increase. G.729 coding and decoding technology occupies small bandwidth and can effectively meet the demand of network course live broadcast teaching platform. Voice communication for which common decoding and coding technology is used needs to occupy 64Kbps bandwidth, but G.729 technology only needs $8 \mathrm{Kbps}$ bandwidth. Such real-time interaction technology can effectively promote interaction instantaneity, effectively relieve network bandwidth burden of the server and reduce operation cost of the server.

\subsection{Monitoring method used for network course terminal, server and learning process}

The main purpose of this monitoring method is to monitor user's behavior of browsing online live video for study with low-load server through database method. Multiple modules are included in the whole monitoring method: video browsing module, logging module and information reporting module. Through video browsing module, online video may be accessed, and corresponding video can be displayed on the above network course terminal. Logging module is connected with the above video browsing module to periodically store video linkage accessed by video browsing module and the access time. Information reporting module is connected with logging module to upload video accessed and access time recorded in the logging module to the external server.

The whole external server technology also includes corresponding modules and server technology: video linkage database which is used to store the linkage of specified videos for corresponding network courses; input module which is used to receive linkage and access time of videos sent by external network course terminal; judging module which is connected with input module and video linkage database, and is used to contrast whether the inputted video linkage is consistent with the video linkage in the database, judge whether the video browsing time conforms to time requirement of 
database and finally confirm whether the learner's study is effective. The structure of system monitoring method is shown in Fig.1.

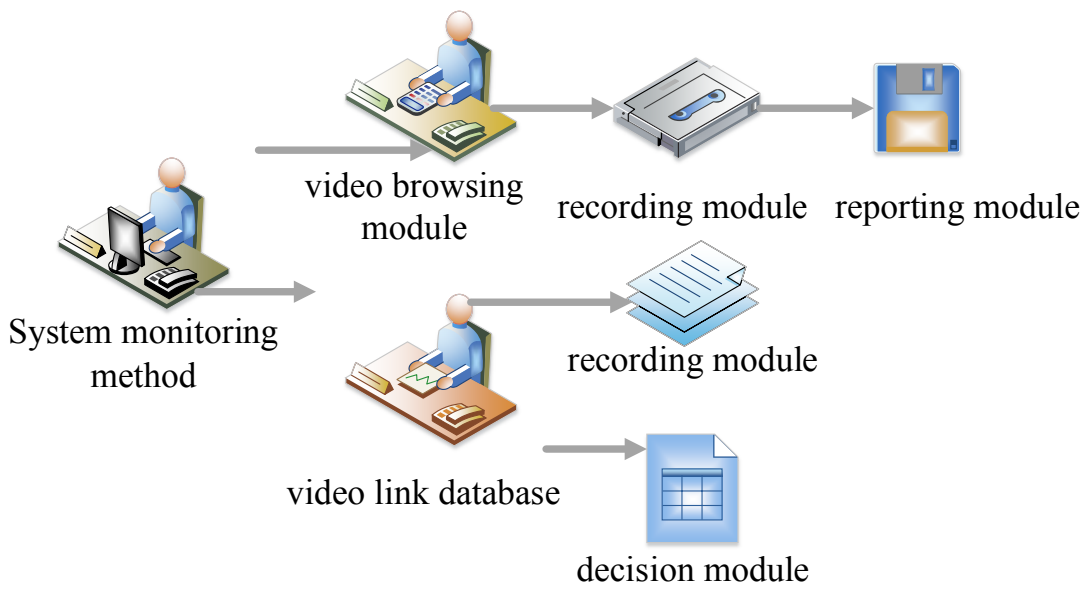

Fig. 1. Structure of system monitoring method

In the monitoring method used for network course terminal, server and learning process, it is most important to confirm whether corresponding time lengthy conforms to server requirements in the whole monitoring process.

\section{$4 \quad$ Physical Training network course live broadcast teaching platform based on real-time interaction mode}

\subsection{Framework of network course live broadcast teaching platform}

Network live broadcast teaching platform in this paper mainly adopts yoga as the teaching course. In the teaching process, yoga practice part is the key. Since the most important factor in yoga practice is the unity of movement, breath and ideology, the teacher and students need to form real-time interaction and exchange in the teaching process, and the teacher should test students' learning situations in real time.

Network live broadcast teaching platform in this paper mainly includes network live broadcast module, real-time interaction module and evaluation module. CSMX technical proposal is chosen for network live broadcast module. Microsoft Visual Studio $\mathrm{C}++6.0$ is used as the development tool. The development language is $\mathrm{C}++$. The feature of CSMX technology is that the whole screen transmission quality is high and transmission data size is small.

Real-time interaction module includes real-time interaction module server and realtime interaction module client. Real-time interaction module server contains:

1. Web server: Visual Studio 2008 is used as the development tool, and the development software is C\#. 
2. Flash Media Sever: Flash CS3 is used as the development tool, and Flash Media Sever ActionScript is used as the development language.

Real-time interaction module client also uses Flash CS3 and Flash Media Sever ActionScript as the development tool and development language respectively. The playing process of network course live broadcast teaching platform is shown in Fig.2.

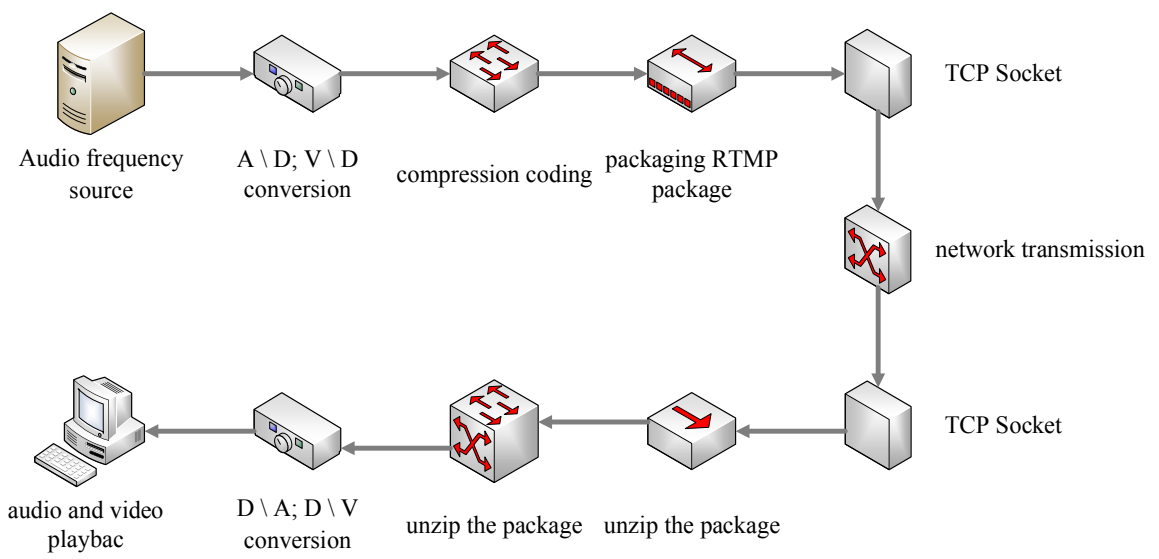

Fig. 2. Process of live broadcast teaching platform system

\subsection{Network live broadcast module}

Network live broadcast module mainly includes two parts: teaching resource collection and teaching resource playing through CSMX technology.

Teaching resource collection. Teaching resource collection requires collection of audio/video information of teachers and capture of corresponding teaching actions in the teaching process. After corresponding information is gathered, data are compressed and transmitted to network terminal server. The development tool of teaching resource collection is Microsoft Visual Studio C ++6.0 , and MFC API is also applied.

Screen capture coding module divides the teacher's screen into 16, and the 16 video areas are monitored by Hook technology. As monitoring process proceeds, corresponding video information is gradually sent to the server through two functions: Hookhandle (UINT Message, HWND hWnd, WPARAM wParam, LPARAM 1Param), and void EncodeScreen*(DSDATAIRP *screen). Hookhandle (UINT Message, HWND hWnd, WPARAM wParam, LPARAM lParam) stores the collected videos in a structure. The other function takes out corresponding code of vide data from screen.

Audio/video collection coding module calls functions void CaptureVideo(char* buf) and void CaptureAudio(char* buf). The two functions collect teacher's audio/video and stores corresponding parameters in the internal storage specified by buf. Then, the functions call void EncodeVideo(char* buf) and void EncodeAudio(char* buf) and code audio/video data in buf. Teaching resource collection process is shown in Fig.3. 


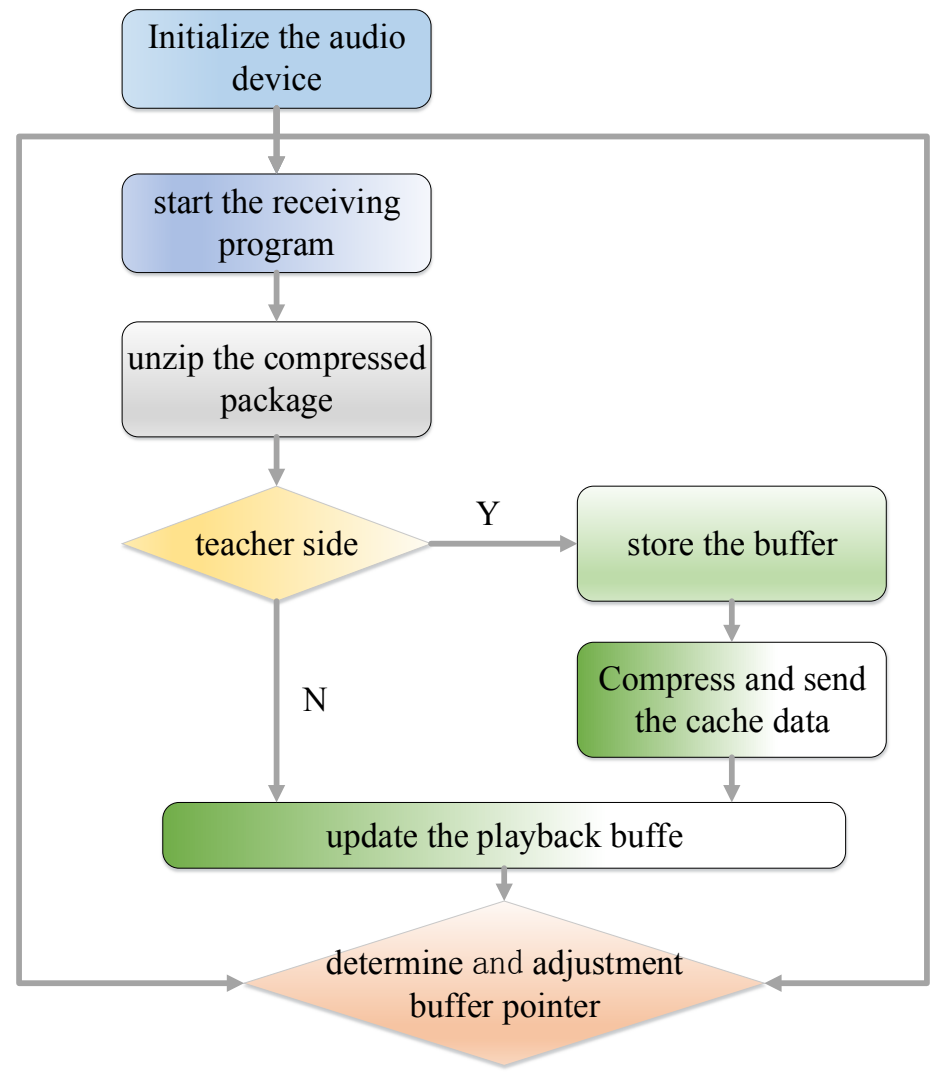

Fig. 3. Teaching resource collection process

Teaching resource playing in CSMX technical proposal. In CSMX technical proposal, teaching resource playing includes audio, video and screen decoding playing. The server transmits the codes of corresponding teaching resources to teaching resource playing module, and the playing module decodes and plays.

In the whole playing process, desynchrony of audio, video and screen needs to be solved. The major solution is as follows: confirm corresponding reference clock for the whole system and confirm corresponding call function as void Play, confirm corresponding time label at the data starting time and ending time. In the whole playing process, the system reads corresponding time label and plays according to the time on the reference clock.

\subsection{Real-time interaction module}

The corresponding real-time interaction module is introduced in the network course live broadcast teaching platform. The teacher and students can discuss in real time through the module. When students encounter problems, they may propose them through audio-video transmission tools such as microphone and camera. The teacher 
may carry out corresponding analysis according to the problems or correct students' movements through the video transmitted by the camera in real time. This module can effectively promote students' classroom study participation and contribute to improving learning efficiency.

Audio/video interaction module mainly includes two parts: video decoding part and network transmission part at the client. In the network transmission part, the realtime interaction module achieves corresponding data sending and reception. Audio video resources implement coding and decoding of audio/video resources through Nellymoser coder and On2Vp6 coder respectively. The transmission process of realtime interaction module is shown in Fig.5.

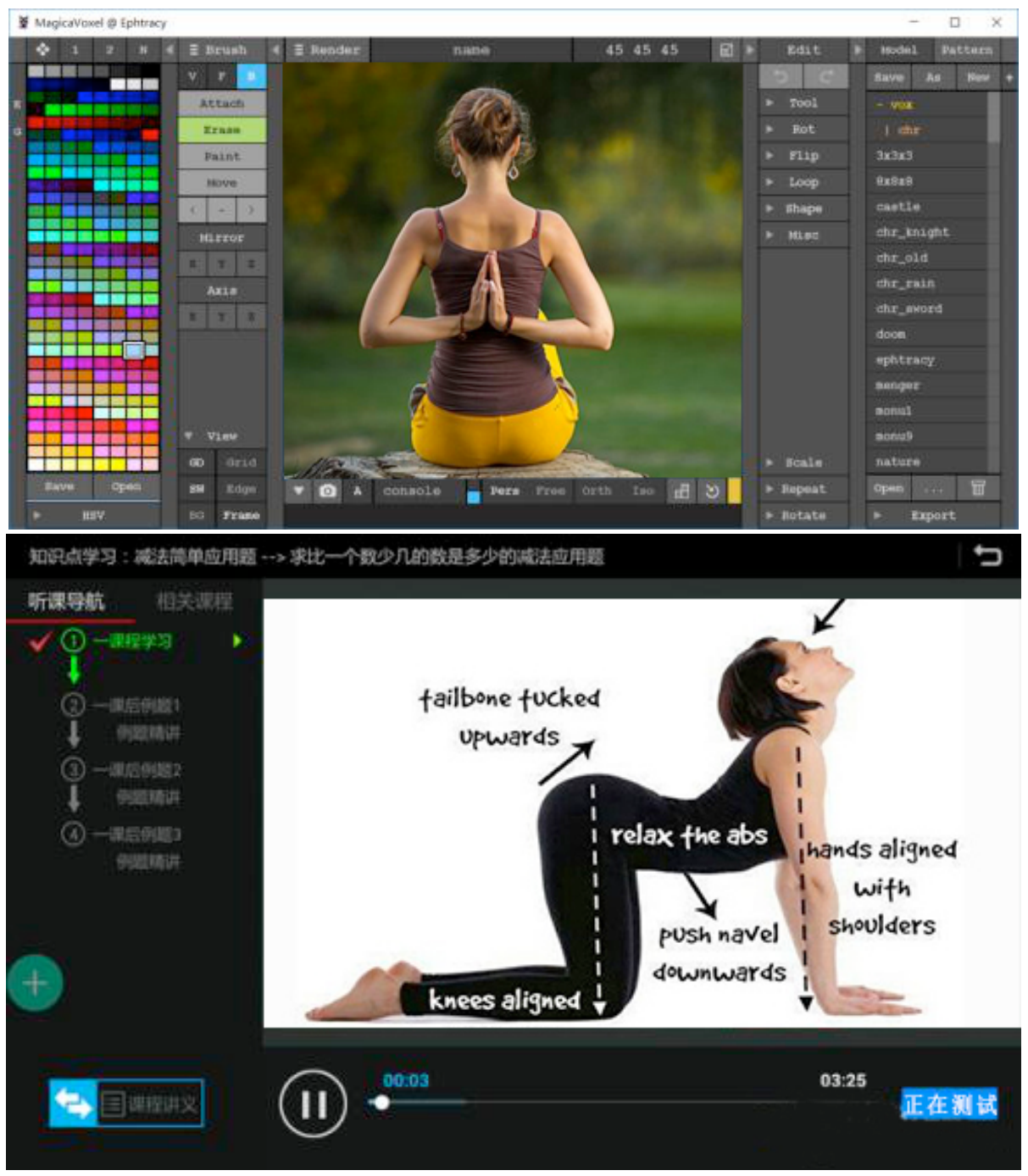

Fig. 4. Learning platform interface 


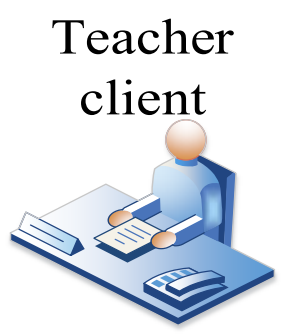

\section{server}

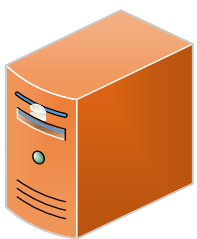

student client

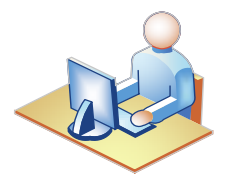

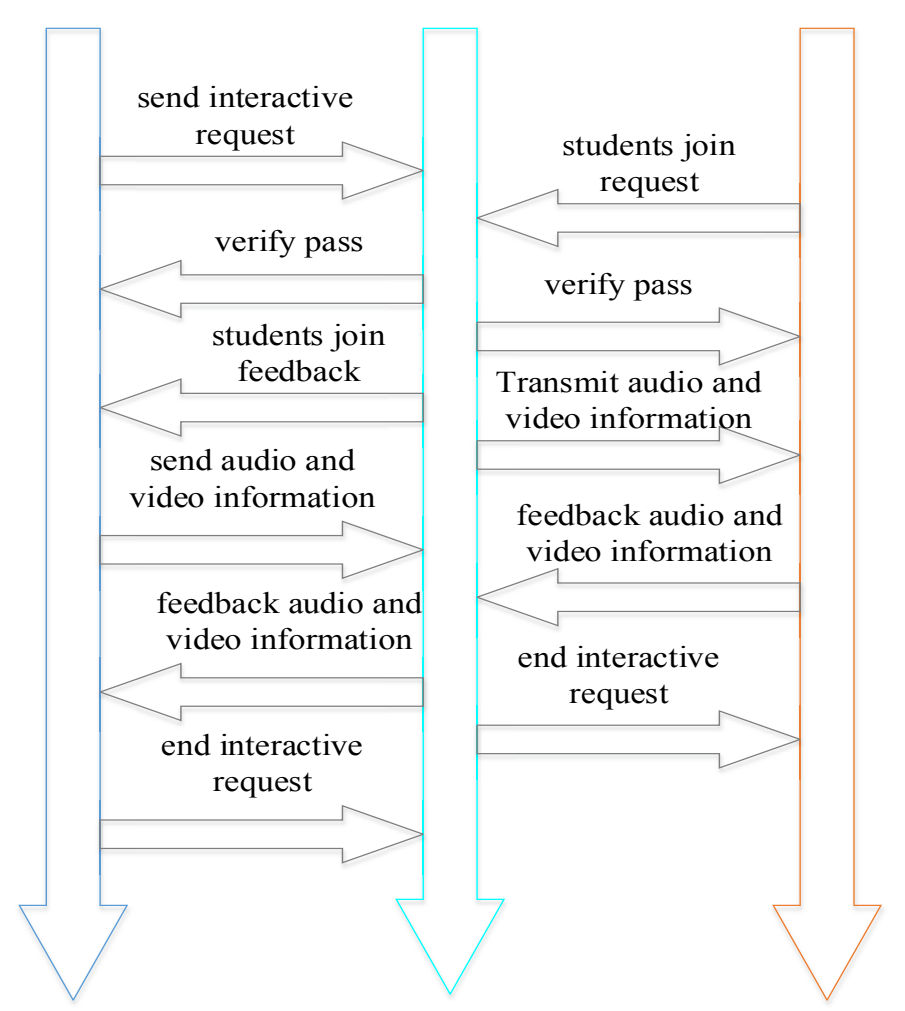

Fig. 5. Transmission process of real-time interaction module

\subsection{Evaluation module}

Evaluation of students' study us also an important part of network course education. Starting from the monitoring method used for network course terminal, server and learning process, this paper establishes comprehensive evaluation system for the network course students. Students' online school time, video viewing time and interaction frequency with the teacher are used as the comprehensive evaluation indexes of Physical Training. The complete process logging module can more effectively promote students to grasp knowledge, and the teacher can better know students' learning performance. Corresponding module analysis of evaluation module is shown in Fig.6. 


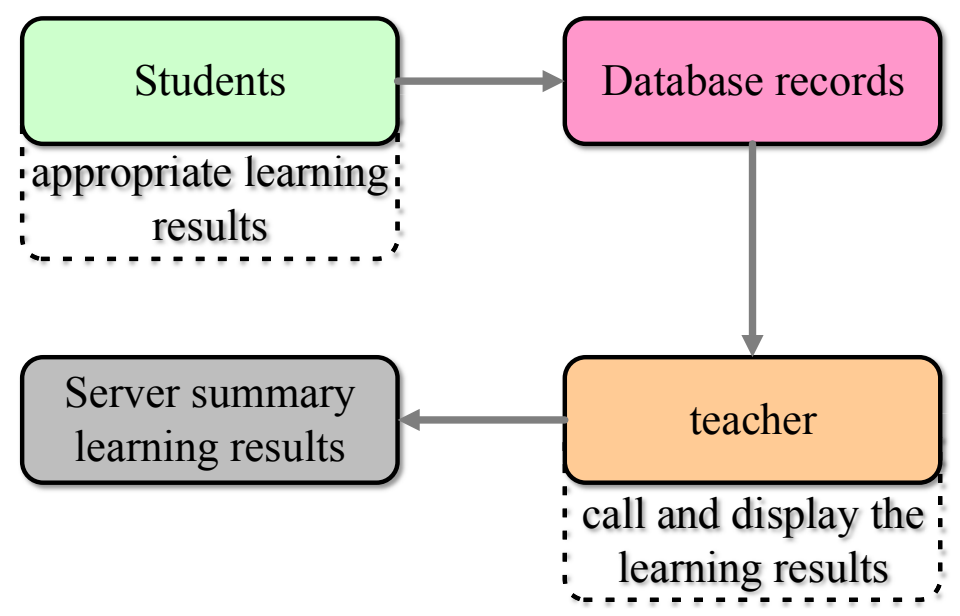

Fig. 6. Structure of evaluation module

\subsection{Effect check}

Before testing the effect of network course live broadcast teaching platform, the author investigated 56 users. Among them, only 5 students had certain understanding of yoga training video and textbook knowledge. The 56 experimental subjects were classified into two groups at random: experimental group (28 students) and control group (28 students). Traditional offline yoga course teaching mode was used for the control group. The network course live broadcast teaching platform was applied for the experimental group. 56 electronic questionnaires were distributed, and all of them were recovered, with the recovery rate of $100 \%$. There were 56 effective questionnaires, with the effective rate of $100 \%$. The data statistics software SPSS was used to analyze the survey result.

Table 1. Yoga movement mastery of both groups

\begin{tabular}{|l|c|c|}
\hline \multicolumn{1}{|c|}{ Group } & $\begin{array}{c}\text { Excellent of Yoga movement } \\
\text { method }\end{array}$ & $\begin{array}{c}\text { Excellent of Essential of Yoga } \\
\text { movement }\end{array}$ \\
\hline Experimental group $(\mathrm{n}=28)$ & $24(85.7 \%)$ & $26(92.8 \%)$ \\
\hline Control group $(\mathrm{n}=28)$ & $16(57.1 \%)$ & $19(67.8 \%)$ \\
\hline
\end{tabular}

It can be seen from Tab. 1 that, the excellence rates of experimental group in yoga movement method and essential of Yoga movement are $85.7 \%$ and $92.8 \%$ respectively, significantly higher than the control group (57.1\% and $67.8 \%)$. This indicates yoga course teaching can effectively improve students' movement method level. Judging from the excellence rates of both groups, the excellence rates of experimental group are $28.6 \%$ and $25 \%$ higher than that of control group. This proves that network course live broadcast teaching platform has good teaching effect. 
Paper-Construction of Real-time Interactive Mode-based Online Course Live Broadcast Teaching ...

Table 2. Comprehensive score of yoga movement in both groups

\begin{tabular}{|c|c|c|c|c|}
\hline Scores & \multicolumn{2}{|c|}{ Experimental group } & \multicolumn{2}{c|}{ Control group } \\
\hline & Number & Percent (\%) & Number & Percent (\%) \\
\hline $0-7$ & 3 & 10.7 & 15 & 32.2 \\
\hline $8-15$ & 25 & 89.3 & 19 & 67.8 \\
\hline Total & 28 & 100 & 28 & 100 \\
\hline
\end{tabular}

After yoga course teaching ended, yoga movement knowledge mastery was tested for both groups. The examination method is that the online teacher uploaded yoga movement video on the learning module, and the offline teacher organized students to view corresponding yoga movement video. According to yoga movement knowledge taught and corrected in the class, 15 wrong movements shown in the yoga movement video were corrected. 1 score was added whenever one wrong movement was found. The proportions of students gaining 0-7 scores and 8-15 scores in the experimental group are $10.7 \%$ and $89.3 \%$ respectively, while the proportions of control group are $53.6 \%$ and $46.4 \%$ respectively. The proportion of experimental group ( $8-15$ scores) is $21.5 \%$ higher than that of control group. This proves that the learning effect of students using network course live broadcast teaching platform is better than that of students who did not use network course live broadcast teaching platform.

\section{Conclusions}

This paper designed and implemented Physical Training network course live broadcast teaching platform based on interaction mode as well as explored the applicability of new teaching mode and method for physical training courses. Meanwhile, after analysis of teaching effect of network course live broadcast teaching platform based on interaction mode, such type of network course teaching can indeed enhance students' learning interest and efficiency during learning physical courses. But, the network course live broadcast teaching platform also has defects and needs to be improved from the following aspects:

1. The teacher's teaching level on the network course teaching platform influences students' learning effect to a large degree. How to evaluate teacher's teaching level? A thorough course teaching evaluation system is required.

2. Since the hardware facilities' and software facilities of the network course live broadcast teaching platform are not mature, the collapse of live broadcast teaching platform and other reasons will reduce students' interest and use. Thus, another problem to be solved is to make network course education platform more stable.

In one word, although there are some problems in the construction of network course live broadcast teaching platform, internet-based learning has become the general trend with the rapid development of information. After in-depth research, the scale of network course teaching will become will be larger, and network course teaching will be full of vigor after current problems are overcome. 


\section{Acknowledgment}

This work was supported by Humanities and Social Sciences General Project of Anhui Provincial Education Department (SK2015B15by).

\section{$7 \quad$ References}

[1] Nickerson, M.F. Online multimedia museum exhibits: a case study in technology and collaboration. Library Hi Tech, 2004, vol. 22(3), pp. 270-276. https://doi.org/10.1108/07378 830410560062

[2] Hughes, G., Dobbins C. The utilization of data analysis techniques in predicting student performance in massive open online courses (MOOCs). Research \& Practice in Technology Enhanced Learning, 2015, vol. 10(1), pp. 10. https://doi.org/10.1186/s41039-015-0007$\mathrm{Z}$

[3] Ranganathan, A., \& Lei, H. Context-aware communication. Computer, 2003, vol. 36(4), pp. 90-92. https://doi.org/10.1109/MC.2003.1193232

[4] Park, J.K., Chung, T.L., \& Hur, W.M. The role of consumer innovativeness and trust for adopting internet phone services, 2011, vol. 3(1), pp. 1-16.

[5] Wu, R., Lo, V., Morra, D., Appel, E., Arany, T., \& Curiale, B., et al. A smartphoneenabled communication system to improve hospital communication: usage and perceptions of medical trainees and nurses on general internal medicine wards. Journal of Hospital Medicine, 2015, vol. 10(2), pp. 83-89. https://doi.org/10.1002/jhm.2278

[6] Inoue-Smith, Y. Pre-service teachers' perceptions of the internet and online courses: the case of an american pacific island university. Asia-Pacific Journal of Teacher Education, 2014, vol. 42(2), pp. 119-131. https://doi.org/10.1080/1359866X.2014.892057

[7] Colombi, E., \& Knosp, S. Teaching dance with online course management systems. Journal of Dance Education, 2017, vol. 17(2), pp. 73-76. https://doi.org/10.1080/1529 0824.2016 .1228108

[8] Freguia, S. Webcasts promote in-class active participation and learning in an engineering elective course. European Journal of Engineering Education, 2017, vol. 42, pp. 1-11. https://doi.org/10.1080/03043797.2016.1192110

[9] Sato, T., Haegele, J.A., \& Foot, R. n-service physical educators' experiences of online adapted physical education endorsement courses. Adapted Physical Activity Quarterly Apaq, 2017, vol. 34(2), pp. 162-178. https://doi.org/10.1123/apaq.2016-0002

[10] Park, K., Lim, Y., \& Suh, D.Y. Delivery of atsc 3.0 services with mpeg media transport standard considering redistribution in mpeg- 2 ts format. IEEE Transactions on Broadcasting, 2016, vol. 62(1), pp. 338-351. https://doi.org/10.1109/TBC.2016.2518625

[11] Guo, S. Evaluation of a web conferencing tool and collaborative tasks in an online chinese course. Research-publishing.net, 2014, vol. 38(17), pp. 241-242.

[12] Fan, L.H., Research on Teaching Methods of Physical Education in China for 30 Years: Process and Progress. Sports Research \& Education, 2017, vol. 24(1), pp. 1-7. 
Paper-Construction of Real-time Interactive Mode-based Online Course Live Broadcast Teaching ...

\section{Author}

Jianqiu Liu is a Lecturer of Bengbu Medical College, Bengbu 233030, Anhui, China. His research interests include physical education and Online Teaching. (815568519@qq.com).

Article submitted 17 March 2018. Final acceptance 23 April 2018. Final version published as submitted by the author. 